\title{
Connecting during times of disconnection: student-teacher partnerships in co-designing online learning
}

\author{
Caelan Rafferty \\ University of Queensland, Australia \\ Kelly E. Matthews \\ University of Queensland, Australia
}

Keywords: Covid-19; students as partners; online learning; co-design.

\section{The challenge}

\section{Caring, uncertainty, and a lack of time}

Months had passed since we had last spoken face-to-face: the brightly-lit lecture theatres, the aroma of freshly-brewed coffee at the nearby café, and the incessant chatter of our crowded campus that we took for granted, distant, faded memories. Instead, we found ourselves locked away in our homes, on beds and kitchen tables, connected via our scheduled Zoom call before disconnecting. Like most students and staff of Australia's higher education community, we had been fundamentally disrupted from our 'normal' ways of interacting, having had to rapidly develop new, digital teaching and learning identities. Indeed, the movement from using technologies as a supplement for being together oncampus pre-pandemic to engaging and interacting with each other online was marked by considerable stress, anxiety, and a dwindling supply of time and energy during 2020 (Vayada, Matthews and Liang, 2020).

We, as strong advocates of 'students as partners' practices, thus found ourselves doubting our capacity to engage in meaningful partnership as our professional and student lives collided with our personal lives during Covid-19 (like many others, see Matthews et al., 2020). Yet, in spite of our doubts, we, the authors and one other student, decided to try by re-designing a second-year Education course as an external, online course together. It was to be the start of a partnership where we agreed and disagreed, laughed, and shared ideas and frustrations. 
For each author, this series of moments crystallised the centrality of partnership in teaching and learning praxis, for while it took time and energy when we were deficient in both, the process energised, motivated, and most importantly, connected us. Another relationship supported by our process was a connection with the students of the course; a connection which the teacher could not nurture, at times, alone. While our partnership ultimately explored the alignment of pedagogy, curriculum, and assessment within the course to ensure coherence, we wish to share with you a snapshot of our pedagogical considerations. Our story will thus focus on our meeting process and the rationale behind the development of our student-led videos.

\section{The response}

\section{Designing together}

Our co-design journey began with a short Zoom meeting - a staple of the times - and, like the beginning of any partnership, it started with a conversation. Indeed, after Kelly, the academic, had briefly outlined the course - a mainly self-directed, external online course with weekly workshops - and the core learning objectives, we then focused on brainstorming together potential online learning activities using the experiences of the student partners, Maggie and Caelan, who had had first-hand exposure to online learning in their first semester.

Following our brainstorming, we settled on developing three activities:

(i) Short (approx. 10 minutes long), informal (made using Zoom without editing) videos featuring a conversation between the student partners where they would discuss the textbook content from their unique perspective (e.g., what they found to be important/interesting/hard to understand/misleading, etc.) (the 'student-led videos').

(ii) Quizzes.

(iii) Discussion questions. 
Moreover, we agreed that each learning activity was to be developed every time new content was introduced into the course. With this shared understanding, we then parted ways with a view to reconvening the following week to outline our progress.

However, when we all met again two days later we had questions for each other. As Maggie and Caelan had started to create the videos, they soon began to doubt their understanding of the content and so sought clarification. Likewise, Kelly, having watched the first set of videos, wondered whether they could be structured differently to better motivate the students. These questions were to be the focus of our second, much-earlierthan-anticipated, meeting. And, following its conclusion, we resolved to tweak aspects of our approach while abandoning others.

Having several unanticipated meetings was to be the norm moving forward on not only the content, but also on deeper, foundational issues like student motivation and learning ethics. Thus, while these meetings ultimately proved to be highly time-consuming, they were also highly entertaining and therapeutic as we laughed at our bloopers, followed generative tangents, and shared frustrations.

As for our student-led videos, they were not only a core component of our partnership effort, they were also a central element of the proposed learning activities. Indeed, the development of the videos assisted both Maggie and Caelan in contextualising the content for developing the quizzes and Kelly in identifying potential roadblocks her students might face come the start of the teaching semester. What is more, this was not their most compelling feature.

Through these videos, Maggie and Caelan modelled the kinds of conversations Kelly wanted her own students to engage in online via their Peer Learning Communities (consistent groups of four students working together weekly). By having the student partners feature as the creators and narrators of the videos, Kelly wanted to legitimise her students as knowledge-holders in her classroom. In letting the student partners take ownership, Kelly sought to demonstrate that she trusted her students to not only take charge of their own learning but to teach others as well.

Overall, feedback for the course was largely positive as shown by the universityadministered student evaluation survey results in Figure 1 which reveals results well- 
above the university average and the highest Kelly has received (to date). Additionally, student feedback on the respective learning activities, collected via weekly, self-evaluation polls, was equally positive. Students' results in progressively developed assessment tasks also improved across the semester as did students' skills in accurately self-assessing, demonstrating clearly to us the strengthens in linking partnership in classrooms with feedback and assessment design (Matthews et al., 2021).

\section{Figure 1. University-administered Student Evaluation Survey.}

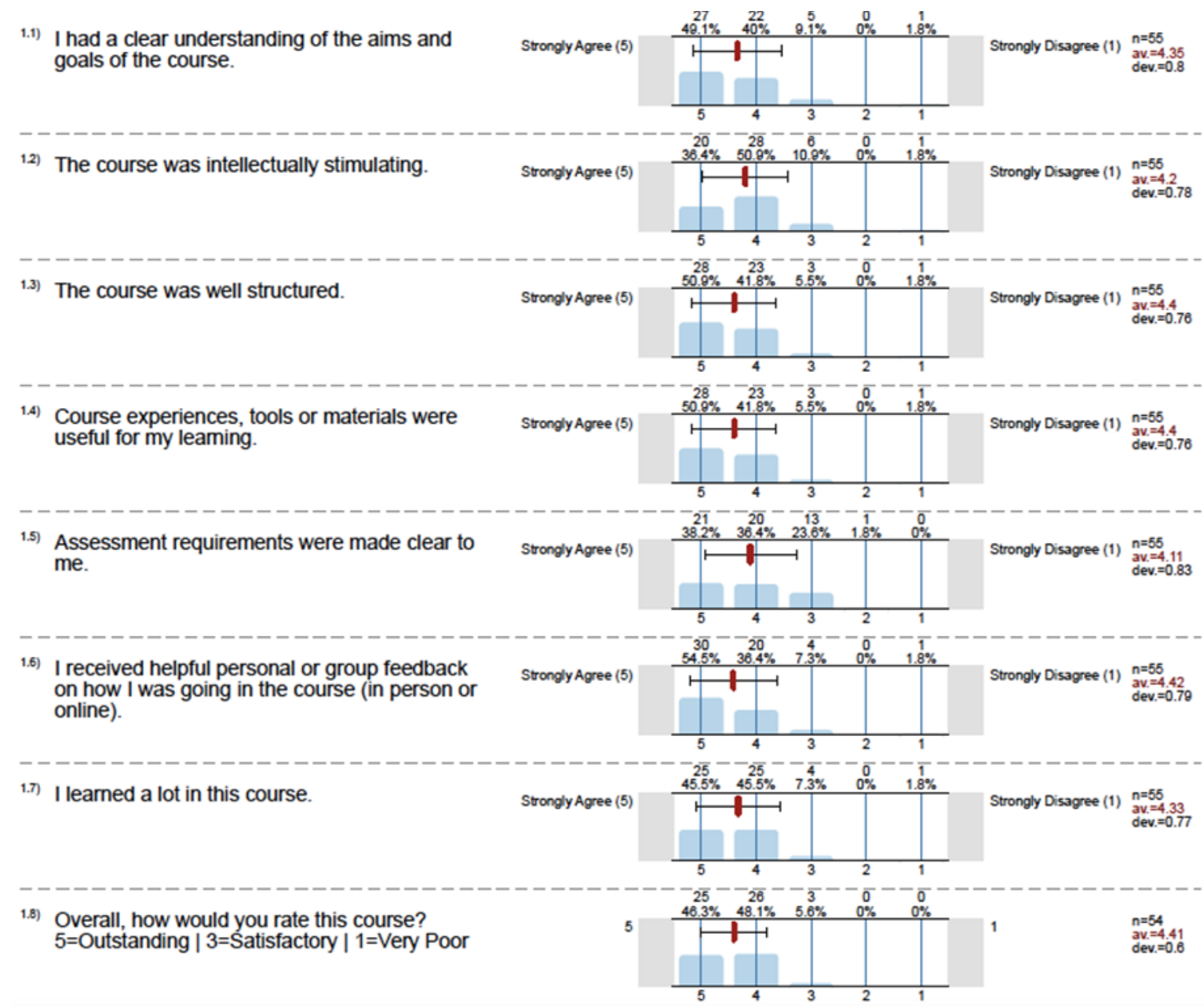

\section{Recommendations}

\section{Partnership as a way forward}

Our partnership experience has reaffirmed our belief in the value of creating shared spaces for dialogue and co-design that engenders recognition between students and staff (Aquarone et al., 2020). Within these spaces, we believe partners should embrace shared responsibility for connecting learning, teaching, and assessment to foster meaningful 
learning interactions in co-designed classes (Matthews, Lawrie and Taptamat, 2021). Forging such partnerships will require a commitment by all partners to both personal and intellectual honesty and recognition that undertaking these processes will take time and energy. By doing so, we will be best placed to chart a sustainable, inclusive way forward as we transition away from remote emergency online education and reconnect postpandemic.

\section{References}

Aquarone, F., Nehéz-Posony, L., Anwar, P. R., Salam, S., Koutsouri, E., Kim, M. and Boodai, Y. (2020) 'We're trying to do things differently': the challenges of relationships and recognition in higher education. London: Centre for Public Policy Research, KCL.

Matthews, K. E., Cook-Sather, A., Godbold, N., Healey, M. and Rafferty, C. (2020) Learner-teacher partnership in times of COVID-19: a community poll to share practices and perspectives [Online poll]. Brisbane: University of Queensland. Available at: https://espace.library.uq.edu.au/view/UQ:66db0d8 (Accessed: 10 May 2021).

Matthews, K. E., Lawrie, G. and Taptamat, N. (2021) Teaching changes due to COVID-19: UQ survey results and case studies. Brisbane: University of Queensland. Available at: https://espace.library.uq.edu.au/view/UQ:294f1e7 (Accessed: 14 May 2021)

Matthews, K. E., Tai, J., Enright, E., Carless, D., Rafferty, C. and Winstone, N. (2021) 'Transgressing the boundaries of "students as partners" and "feedback" discourse communities to advance democratic education', Teaching in Higher Education, pp.1-15. https://doi.org/10.1080/13562517.2021.1903854.

Vayada, P, Matthews. K .E. and Liang, Y. (2020) 'We are all in it together', Higher Education Research and Development Society of Australasia Connect, 42 (3), pp. 15-15. Available at: https://www.herdsa.org.au/sites/default/files/HERDSA\%20CONNECT\%20\%20spring\%202020.pdf (Accessed: 10 May 2021). 


\section{Author details}

Caelan Rafferty is a former student from the University of Queensland. At UQ, Caelan was involved in shaping UQ's 'Students as Partners' (SaP) model from 2017 (until 2020) when he joined the UQ SaP Committee and Pilot Projects as an undergraduate. Caelan has engaged in several UQ SaP projects, is a co-editor for the International Journal for Students as Partners (IJSaP), and has co-facilitated the International SaP Institute (in 2019).

Kelly E. Matthews is an Associate Professor and internationally recognised SaP practitioner/researcher from the University of Queensland. Kelly is a co-editor for the International Journal for Students as Partners (IJSaP), has co-facilitated the International SaP Institute (in 2016, 2018, and 2019), has given 30+ talks on SaP inter/nationally, and is a leader of the Australian 'SaP Network' with $800+$ members. 